\title{
O aplicativo Perfect Piano como recurso digital no Ensino Remoto de música em tempos de Pandemia
}

\author{
Tereza C. D. C. V. Carvalho', Priscila B. David ${ }^{1}$ \\ ${ }^{1}$ Instituto UFC Virtual - Programa de Pós-Graduação em Tecnologia Educacional - \\ Universidade Federal do Ceará (UFC) \\ Caixa Postal 60455 - 760 - Fortaleza - CE - Brazil \\ tiaterezadourado@gmail.com, priscila@virtual.ufc.br
}

\begin{abstract}
The article aims to present the project "Music and Technology in Our House", highlighting the contributions, limitations, procedures and methodology through the use of Perfect Piano and other TDIC for remote music teaching. To achieve the objectives, an action-research was used remotely with 20 students from the 3rd to the 5th year of elementary school in a public school in the municipality of Maracanaú-Ceará, between March and December 2020. The results showed that the strategies adopted from the creation of a project, they promoted bonding, interaction and affectivity in the context of the Covid19 pandemic.
\end{abstract}

Resumo: $O$ artigo tem como propósito apresentar o projeto "Música e Tecnologia na Nossa Casa”, destacando as contribuições, limitações, procedimentos e metodologia mediante o uso do Perfect Piano e outras TDIC para o ensino remoto de música. Para alcançar os objetivos, recorreu-se a uma pesquisa-ação realizada remotamente com 20 alunos do $3^{\circ}$ ao $5^{\circ}$ ano do Ensino Fundamental de uma escola pública do município de Maracanaú-Ceará, entre março e dezembro de 2020. Os resultados apontaram que as estratégias adotadas a partir da criação de um projeto, promoveram o vínculo, a interação e a afetividade no contexto da pandemia da Covid-19.

\section{Introdução}

A pandemia da COVID-19 impôs uma nova ordem e um outro ritmo para a humanidade, afetando todos os setores sociais, sobretudo, o da Educação. O cotidiano sofreu uma grande metamorfose e, por conta do avanço do contágio pelo novo coronavírus, as escolas precisaram se organizar e migrar suas atividades para o ensino remoto. Houve uma adaptação provisória de aulas presenciais para aulas on-line mediadas por tecnologias digitais [Rodrigues 2020]. Ademais, os professores tiveram que encontrar estratégias e metodologias a fim de tornar as aulas mais dinâmicas, atrativas e, de alguma forma, prover a interação entre os estudantes. Sob esse viés, de acordo com Souza (2020), no período pandêmico, novas relações afetivas e profissionais foram construídas e muitas pessoas passaram a trabalhar remotamente.

Ao buscar tais estratégias para o envolvimento dos alunos no cenário atual, evidenciou-se um amplo "leque" de Tecnologias Digitais da Informação e Comunicação (TDIC) na área de música, como os aplicativos (apps) musicais que são recursos digitais com capacidade de abranger uma diversidade de funções. Nesse contexto, a utilização dos referidos apps atua como um instrumental que pode incorporar elementos favoráveis ao exercício do professor, recorrendo à interação e à colaboração entre educadores em 
todo o território brasileiro. De acordo com Chamorro et al. (2017), as TDIC são recursos tecnológicos digitais que auxiliam, reúnem, distribuem e compartilham informações na pesquisa, no ensino e em várias áreas.

Na Educação Básica do Brasil, a linguagem musical está atrelada ao componente curricular de Artes. A lei mais recente, Lei de Diretrizes e Bases da Educação Nacional (LDB) $\mathrm{n}^{\circ} 13.278 / 16$, altera o $6^{\circ}$ parágrafo da LDB 9.394 de 1996, determinando que o ensino de música na educação básica deve ser conteúdo obrigatório da disciplina de Artes, juntamente com as artes visuais, a dança e o teatro [Brasil 2016]. Vale ressaltar que o estudo da linguagem musical não deve ser limitado ao componente curricular de artes. De acordo com a Base Nacional Comum Curricular (BNCC), os temas, os assuntos e/ou as habilidades afins de diferentes componentes podem compor projetos nos quais os saberes se integrem, gerando experiências amplas e complexas de aprendizagem [Brasil 2017].

Assim, o presente artigo agrega grande relevância ao campo educacional brasileiro, uma vez que articula o conhecimento de música por meio do uso de recursos digitais e de outras disciplinas ou conteúdos, os quais, de forma multidisciplinar, buscam o desenvolvimento integral do ser humano, visando melhor prepará-lo para a vida em sociedade. Segundo a BNCC, o uso das TDIC está previsto com o objetivo de serem utilizadas de maneira crítica e responsável pelos alunos ao longo da Educação Básica [Brasil 2017]. Sob esse âmbito, buscou-se responder ao seguinte questionamento: Quais estratégias podem ser desenvolvidas para a promoção do ensino de música remotamente, possibilitando o vínculo, a interação e a afetividade entre os alunos dos anos iniciais do Ensino Fundamental diante do contexto da pandemia da Covid 19?

Pressupõe-se que este trabalho, a partir de um projeto voltado ao ensino da linguagem musical por meio de recursos digitais, mesmo que remotamente, possa contribuir de uma maneira relevante para a promoção do vínculo, interação e afetividade entre os alunos. Tais possibilidades se concretizam mediante o uso de apps, redes sociais e encontros em plataformas de videoconferências para o compartilhamento de performances, conteúdos, dinâmicas e envolvimento entre os pares.

Desse modo, a presente pesquisa objetiva apresentar o projeto "Música e Tecnologia na Nossa Casa", desenvolvido com alunos dos anos iniciais do Ensino Fundamental de uma escola pública do município de Maracanaú-Ceará, cujo intuito foi promover a educação musical em um ambiente remoto de prática educacional multidisciplinar mediado pelas TDIC. Os objetivos específicos são: destacar as contribuições e limitações mediante o uso do Perfect Piano e outras TDIC para o ensino remoto de música; descrever os procedimentos utilizados para o compartilhamento dos conteúdos e para a articulação do vínculo, interação e afetividade entre o professor e alunos; e revelar a metodologia aplicada para compartilhar o desempenho dos alunos a um público externo e também avaliar os estudantes.

$\mathrm{O}$ artigo está estruturado em cinco seções. Além da introdução, que apresenta a relevância, a questão e o propósito, o trabalho está dividido em mais quatro seções. A seção 2 apresenta recursos digitais no ensino de música. Na seção 3, são mostrados os aspectos metodológicos empregados na análise dos dados do estudo. $\mathrm{Na}$ seção 4, consideram-se os resultados obtidos e a discussão deles. Por fim, a seção 5 elenca as considerações finais. 


\section{Recursos Digitais no Ensino de Música}

Atualmente, dispositivos, como smartphones e tablets, são recursos tecnológicas móveis que podem servir como suporte às práticas pedagógicas a partir de aplicativos para o ensino de música nas escolas. As facilidades que esses aparelhos trazem para professores, pais e alunos são enormes, e sua implantação é algo que poderia transformar a Educação. De acordo com Duarte (2014), os smartphones são aparelhos celulares que possuem tecnologias mais avançadas do que os aparelhos comuns, e os tablets dizem respeito a modelos de computadores para uso geral, compostos basicamente por uma tela sensível ao toque, chamada touchscreen.

É importante considerar que, com o crescimento dos recursos digitais, o uso de aplicativos musicais no processo de ensino e aprendizagem de música implica uma série de decisões que vão do aspecto técnico ao aspecto pedagógico. Nesse sentido, Cota (2016) ressalta que os aplicativos musicais cumprem as mais diversas funções, como ferramentas para musicalização, jogos musicais, mecanismos úteis para músicos profissionais e instrumentos virtuais.

Embora o professor possa recorrer a qualquer um desses recursos digitais como suporte pedagógico, é necessário que ele busque uma metodologia que o contextualize no processo de ensino e aprendizagem de música. Sob tal perpectiva, inquere-se: Como selecionar um aplicativo musical diante da ampla disponibilidade e variedade no contexto atual? Assim, os docentes assumem um papel fundamental para a integração dos recursos digitais ao ensino de música, sendo eles responsáveis pela escolha. Isso porque a seleção minimalista dos recursos serve para melhorar a transferência de habilidades e de conhecimentos dos professores para os alunos [Cheng e Leang 2017].

Além disso, ressalta-se que uma condição a ser considerada durante a escolha de recursos é o uso de aplicativos livres, ou seja, gratuitos, uma vez que o custo para implantar nos smartphones e tablets poderia ser obstáculo para a utilização de aplicativos no ensino [Miyamoto e Montanha 2016]. Como reflexo das escolhas supracitadas, destaca-se como uma das vantagens dos aplicativos musicais para a Educação: a possibilidade de combinar os estudos teóricos e práticos, por meio dos quais o aluno escolhe seu ritmo, seu horário e seu local de estudo. Como desvantagem, Mota (2019) aponta para o fato de que os sons simulados pelos aplicativos não têm o mesmo resultado sonoro que a experiência com o instrumento real.

Consoante Miyamoto e Montanha (2016), alguns aplicativos já se tornaram essenciais para o auxílio do ensino das práticas musicais na composição e improvisação, como os metrônomos, os afinadores, os instrumentos virtuais e as plataformas para gravação de áudio. Desse modo, serão detalhadas, a seguir, as funcionalidades do Perfect Piano, cujo aplicativo musical simula o instrumento virtual "Piano" e pode ser utilizado para dar suporte ao processo de ensino e aprendizagem de música na Educação.

\subsection{O Aplicativo Perfect Piano}

A quantidade de aplicativos musicais nas lojas virtuais é enorme e seria impossível elencar todos ou mesmo fazer uma lista dos principais. Segundo Cantão (2018), o Perfect Piano é um dos principais aplicativos apontados em pesquisas na Play Store da Google mediante o uso do termo "aplicativo piano". 
Vale ressaltar que, ao realizar o estado da arte por meio da string de busca "(applications OR software) AND ("teaching music" OR "music education") AND ("elementary school")", na base de dados Scopus, o estudo "Training the non-specialist music teacher: Insights from an Indonesian action research study", escrito por Julia et al. (2020) apontou que o ensino de música auxiliado pelo aplicativo tornou o conhecimento mais fácil. Ademais, com o uso da mesma string de busca, a base de dados Eric indicou o estudo "Shifting Primary School Teachers Understanding of Songs Teaching Methods: An Action Research Study in Indonesia”, no qual Julia et al. (2019a) revelou que o app Perfect Piano é um exemplo de aplicativo para orientação do tom vocal.

Percebe-se que nos estudos acima mencionados e que foram desenvolvidos na Indonésia, houve a utilização do recurso digital para ampliar os conhecimentos e habilidades dos professores de música (especializados ou não). O intuito dos estudos foi apontar as possibilidades para o ensino de música e criar caminhos para a ampliação das competências musicais dos alunos mediante tecnologias digitais.

Em suma, o app Perfect Piano foi projetado para aparelhos com o sistema operacional Android, como smartphones e tablets. Possui uma interface composta de seis módulos: Aprenda a reproduzir; Teclado; Jogo para multijogadores; Conexão multijogadores; Piano cicle e Gerenciador de registros. O módulo "Teclado" trata-se de um simulador de piano inteligente que possui um timbre genuíno de piano embutido e outros instrumentos musicais. De acordo com Julia et al. (2019b), o Perfect Piano pode ser utilizado para treinar os professores a ensinarem melodias para seus alunos.

É importante salientar que, no Perfect Piano, os usuários podem gravar suas performances que ficam registradas em uma galeria dentro do aplicativo como arquivo Musical Instrument Digital Interface (MIDI). Na concepção de Gohn (2010), as tecnologias MIDI são bases eletrônicas para tocar música, definindo quais notas e timbres devem soar em um determinado momento. Elas têm uma comunicação padronizada, proporcionando uma composição que seja desenvolvida, propagada ou empregada por qualquer dispositivo que reconheça tal padrão. Além disso, os arquivos podem ser compartilhados em formato de áudio para o WhatsApp e outras plataformas digitais.

\section{Metodologia}

A pesquisa de natureza aplicada teve uma abordagem qualitativa, pressupondo a compreensão do estudo realizado no modelo remoto com 20 alunos do $3^{\circ}$ ao $5^{\circ}$ ano do Ensino Fundamental I de uma Escola Pública do Município de Maracanaú, Ceará. Ademais, vale ressaltar que algumas variáveis e dados de natureza quantitativa foram utilizados e coletados para o levantamento de opiniões dos alunos.

Para alcançar os objetivos, realizou-se a pesquisa-ação caracterizada pela interação entre sujeitos e pesquisadores na produção de novos conhecimentos. De acordo com Fillipo et al. (2021), a pesquisa-ação possui um duplo objetivo: por meio da pesquisa oportuniza-se a ampliação do conhecimento científico e por meio da ação articula-se uma melhoria para uma adversidade real que ocorre no ambiente particular onde a investigação é realizada. Neste método o pesquisador não pretende apenas compreender ou descrever o mundo da prática, mas também transformá-lo. Vale ressaltar que uma das investigadoras da experiência é também a professora responsável pelo projeto, a qual buscou em concordância com a gestão da escola o aprendizado de seus alunos por meio 
da linguagem musical mediante o uso de recursos digitais, objetivando promover o vínculo, a interação e a afetividade dos estudantes em tempos difíceis, como o vivido no contexto atual.

\subsection{Materiais Experimentais e Instrumentos de Coletas de Dados}

Para o experimento, foi utilizado o aplicativo Perfect Piano instalado em smartphones e tablets, bem como o app WhatsApp (usado para as interações assíncronas por meio de troca de mensagens e comunicação em áudio e vídeo), além das plataformas digitais Google Meet e Messenger, tendo o propósito de promover a interação síncrona entre os estudantes. Para Santos (2020), as atividades assíncronas são aquelas que se configuram pelo afastamento geográfico e pela divisão diferente de tempo de comunicação. Já as atividades síncronas geram relações afetivas sensacionais que permitem proferir conversas e encerrar ciclos de debates. No que tange ao Google Meet, Sant'Anna e Sant'Anna (2020) afirmam que é um recurso de interação por meio de videoconferência, de fácil manuseio e que pode ser utilizado de forma gratuita.

Quanto ao apoio pedagógico para o desenvolvimento das canções no aplicativo Perfect Piano, foi utilizado o site Cifra Melódica, tendo em vista que ele compartilha por meio de letras e de símbolos gráficos, as notas musicais a serem executadas por um instrumento melódico. Em concordância com a BNCC, a ação de explorar diferentes formas de registro musical convencional e não convencional traduz-se em habilidades que devem ser contempladas para a ampliação dos conhecimentos musicais pelos estudantes [Brasil 2017].

Com base nos objetivos traçados e nos tipos de pesquisas assinalados, foram utilizadas como técnicas para a coleta de dados: a observação participante ao longo de todo o processo, as práticas de conversação, as entrevistas semiestruturadas e a análise documental. De acordo com Correia (2009), a observação participante é realizada no convívio direto, frequente e prolongado do investigador com os atores sociais, nos seus contextos culturais, sendo o próprio investigador instrumento de pesquisa.

Os instrumentos utilizados foram: diários de campo para documentação das observações verificadas, questionários on-line, registros audiovisuais e fotográficos enviados pelos alunos e contidos nas redes sociais da escola. A partir das observações realizadas nos encontros e dos vídeos e fotos enviados pelos alunos, tornou-se possível avaliar o impacto do projeto no cotidiano dos estudantes.

\subsection{Local, Participantes e Procedimentos}

Com o intuito de tentar responder à problemática apresentada na introdução deste artigo, o projeto Música e Tecnologia na Nossa Casa apresentou-se como um universo de possibilidades para o ensino remoto de música, contendo uma carga horária semanal de 2 horas-aula, estas realizadas às sextas-feiras, com atividades que aconteceram entre os meses de março e dezembro de 2020. O objetivo da ação foi promover a educação musical em um ambiente remoto de prática educacional multidisciplinar mediado pelas tecnologias digitais, oportunizando o vínculo escolar, a afetividade e a interação no contexto da Pandemia da COVID-19. Segundo Volpe (2018), o termo multidiciplinaridade reconhece a precisão de intensificar o diálogo entre as diversas áreas de conhecimento. 
O projeto foi conduzido pela professora de informática e contou com a participação de 20 alunos de uma escola pública pertencente à Rede Municipal de Ensino em Maracanaú-Ceará. A instituição está localizada na zona urbana, periferia da região metropolitana de Fortaleza, sendo marcada pela vulnerabilidade social, ou seja, a maioria da clientela pertence à classe econômica desfavorável.

Segundo informações fornecidas pelo secretário da Escola, o qual participa anualmente do Censo Escolar, a Unidade oferece os seguintes níveis de ensino: Creche (crianças de três anos), Educação Infantil (Pré I e Pré II) e Ensino Fundamental ( $1^{\circ}$ ao $5^{\circ}$ ano), totalizando 339 alunos matriculados. Com o advento da pandemia, as aulas da escola passaram a ser remotas e, com o propósito de seguir atendendo os estudantes de forma democratizada, foi usada a ferramenta WhatsApp, por meio da qual houve a criação de grupos para cada turma, possibilitando, assim, o compartilhamento de vídeos e de atividades pelos professores.

As divulgações acerca do projeto foram transmitidas aos alunos via grupos de WhatsApp já existentes e criados pela escola, por meio dos quais as aulas remotas das turmas do $3^{\circ}$ ao $5^{\circ}$ ano do Ensino Fundamental aconteceram. Para a inscrição, os alunos interessados em participar do projeto deveriam se manifestar de forma espontânea, enviando uma mensagem em particular para a professora responsável pela proposta.

Em decorrência disso, os alunos inscritos foram reunidos em outro grupo específico do WhatsApp, cuja descrição no perfil continha o nome do projeto, visando criar um vínculo afetivo e promover a interação dos estudantes com a professora e seus pares. Por intermédio da ferramenta em questão, foram disponibilizadas as agendas com as informações, as videoaulas e as atividades para os alunos. A cada semana, a professora disponibilizava um vídeo e uma atividade a serem desenvolvidos pelo aluno e, na semana seguinte, a aula era realizada a partir de plataformas digitais, como o Google Meet ou o Messenger.

\section{Análise e Discussão dos Resultados}

O presente estudo está relacionado com outros trabalhos, como os de Barbosa e Dourado (2016), Dourado (2018) e de Sousa (2019), cujos autores tiveram o objetivo de mostrar a relevância do uso das tecnologias no ensino de música na escola a partir de um projeto pedagógico no formato presencial. Entretanto, este artigo se diferencia por identificar as possibilidades e estratégias para o ensino de música no contexto da pandemia da COVID19, criando oportunidades para o vínculo escolar, a afetividade entre os pares e a interação no ensino remoto, conforme serão detalhadas a seguir.

\subsection{Contribuições e Limitações mediante o Uso do Perfect Piano e outras TDIC para o Ensino Remoto de Música}

Como estratégia e ferramenta principal para o ensino remoto de música recorreu-se ao aplicativo Perfect Piano. Pelo aplicativo musical, os alunos aprenderam por meio da simulação de um piano a tocar melodias que engrandeceram a cultura, a arte, os valores e a diversidade.

A seleção do Perfect Piano pela professora deveu-se ao fato do aplicativo proporcionar a aprendizagem de música em qualquer ambiente, seja dentro de casa ou na escola, com a possibilidade de gravação do áudio das performance dos alunos e o seu compartilhamento no formato MIDI. No projeto, semanalmente, os alunos recebiam as 
notas musicais de uma canção, e cada um deles, respeitando seu tempo e ritmo, treinava em suas residências para a apresentação na aula seguinte, via Google Meet. Ademais, alguns alunos gravavam suas performances utilizando um aplicativo de gravação de tela de smartphones (ver Figura 1) ou compartilhavam o áudio disposto no app pelo grupo de WhatsApp. De acordo com Miyamoto e Montanha (2016), um dos grandes benefícios dos recursos digitais móveis na Educação é a possibilidade de aprender momentaneamente, sem barreiras de tempo e de espaço físico.

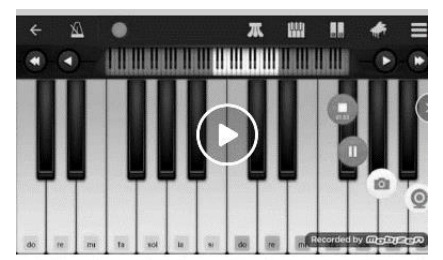

\section{Figura 1: Performance do aluno no aplicativo Perfect Piano utilizando o gravador de tela}

Conforme Filippo et al. (2021), uma das características da pesquisa-ação é o envolvimento dos sujeitos em colaboração com o pesquisador. Nesse viés, realizou-se uma enquete com os alunos a partir de um questionário on-line semiestruturado, com o intuito de obter feedback sobre a utilização do aplicativo. No total, 12 alunos responderam à pesquisa, sendo $71,4 \%$ do $5^{\circ}$ ano e $28,6 \%$ do $3^{\circ}$ e $4^{\circ}$ anos. No que tange ao sexo,71,4\% dos participantes foram do sexo feminino e $28,6 \%$ do sexo masculino, com uma idade que variou entre 8 e 11 anos.

Quando questionados sobre o que mais gostaram no app Perfect Piano, destacaram-se algumas falas: "Do piano"; "Do som"; "Posso aprender a tocar várias canções"; "Não precisa de internet para utilizá-lo"; "Eu gostei de tudo"; "Os timbres que você pode colocar para tocar" e "Eu amei o jogo". Quanto ao aprendizado de música com o recurso digital, indicaram que aprenderam a identificar as notas musicais, desenvolveram a habilidade de tocar canções, conseguiram gravar as suas performances, compartilharam os áudios e compreenderam o que são as oitavas em um piano musical.

No que tange às limitações encontradas para a utilização do recurso digital, destacaram-se: a memória insuficiente para baixar o aplicativo, a escassez da internet e a falta de compreensão dos affordances dispostos no app. Com relação à memória insuficiente, na observação participante, foi identificada que uma das dificuldades de baixar o app estava associada ao acúmulo de aplicativos existentes em seus recursos tecnológicos, como o Google Meet, o gravador de tela, dentre outros apps utilizados não só pelos alunos, mas também pelos seus familiares. Todavia, para remediar problemas com memória, foi enviado como sugestão um link de um piano virtual via web, para que eles não deixassem de realizar a atividade.

No que tange à escassez da internet, vale ressaltar que, para o uso do Perfect Piano, a rede é utilizada apenas no momento de baixar o app disposto na play store dos recursos tecnológicos. Contudo, para os momentos de interação da turma, a professora utilizou-se do Google Meet e o do WhatsApp, na qual alguns alunos apresentaram dificuldades no acesso. Vale enfatizar que, algumas vezes, a rede social Messenger foi utilizada para momentos síncronos de interação, tendo em vista que ela possibilitava o uso sem a necessidade dos estudantes realizarem o download em suas ferramentas tecnológicas. De acordo com Sant'Anna e Sant'Anna (2020), muitos alunos não possuem 
condições financeiras para assinar uma internet banda larga ou uma conexão de dados móveis.

Por fim, no que se refere às dificuldades de compreensão dos affordances dispostos no app, foram todos superados com as explicações a partir de videoaulas disponilizadas pela professora. De acordo com Barbosa e Silva (2010), o affordance é um conjunto de características dos objetos de interface que mostram aos seus usuários como tais objetos podem ser manipulados.

\subsection{Procedimentos Utilizados para o Compartilhamento dos Conteúdos e para a Articulação do Vínculo, Interação e Afetividade entre o Professor e os Alunos}

No início do projeto, foram elaboradas videoaulas sobre técnicas necessárias à utilização do aplicativo Perfect Piano, incluindo a exploração de conceitos básicos da teoria musical, dentre eles: as notas musicais e suas relações de altura; os elementos constitutivos da música, como ritmo, harmonia, melodia e os timbres de instrumentos musicais. De acordo com a BNCC, perceber e explorar os elementos constitutivos da música por meio de jogos, brincadeiras, canções e outros são habilidades necessárias para o aprendizado da linguagem musical [Brasil 2017].

O projeto não se limitou ao conteúdo de música do próprio aplicativo, mas houve expansão para um estudo multidisciplinar de outros conteúdos, agregando valores e propiciando o desenvolvimento integral do aluno, conforme mostra o Quadro 1.

Quadro 1: Conteúdos do trabalhado no projeto e aspectos desenvolvidos no aluno

\begin{tabular}{|c|c|c|c|}
\hline Conteúdo de música & $\begin{array}{c}\text { Conteúdo } \\
\text { multidisciplinar }\end{array}$ & $\begin{array}{c}\text { Repertório musical } \\
\text { (Exemplos) }\end{array}$ & $\begin{array}{c}\text { Aspectos do } \\
\text { desenvolvimento }\end{array}$ \\
\hline $\begin{array}{c}\text { Elementos constitutivos da } \\
\text { música: ritmo, melodia e } \\
\text { harmonia }\end{array}$ & $\begin{array}{c}\text { Resgate às } \\
\text { cantigas de roda e } \\
\text { infantis }\end{array}$ & $\begin{array}{c}\text { Atirei o pau no gato, } \\
\text { Ciranda cirandinha, } \\
\text { Borboletinha etc. }\end{array}$ & Motores \\
\hline $\begin{array}{c}\text { Percepção musical/ } \\
\text { Sonoplastia: explorar } \\
\text { fontes sonoras diversas }\end{array}$ & $\begin{array}{c}\text { Cultura regional: } \\
\text { festas juninas/ } \\
\text { folclore }\end{array}$ & $\begin{array}{c}\text { Asa Branca, } \\
\text { Luar do Sertão, } \\
\text { Pombinha Branca etc. }\end{array}$ & Cognitivos \\
\hline $\begin{array}{c}\text { Instrumentos musicais } \\
\text { (PIANO) }\end{array}$ & $\begin{array}{c}\text { Valorização da } \\
\text { pátria }\end{array}$ & $\begin{array}{c}\text { Hinos (Nacional, Municipal } \\
\text { e da Independência) }\end{array}$ & Emocionais \\
\hline $\begin{array}{c}\text { Notação musical } \\
\text { planetária }\end{array}$ & $\begin{array}{c}\text { Paródias sobre os cuidados } \\
\text { com a natureza }\end{array}$ & $\begin{array}{c}\text { Socialização e } \\
\text { Interação }\end{array}$ \\
\hline Cidadania digital \\
comprovisações e & $\begin{array}{c}\text { Paródias sobre fake news, } \\
\text { Pedofilia, internet segura }\end{array}$ & $\begin{array}{c}\text { Autonomia e } \\
\text { Resiliência }\end{array}$ \\
\hline Repertório musical & Valores & $\begin{array}{c}\text { Canções da Música Popular } \\
\text { Brasileira (MPB) e paródias }\end{array}$ & $\begin{array}{c}\text { Consciência } \\
\text { ambiental e } \\
\text { digital }\end{array}$ \\
\hline Paródias & Religiosason (Natal) & $\begin{array}{c}\text { Bom Natal, } \\
\text { Bate o Sino }\end{array}$ & \begin{tabular}{c} 
Valores éticos \\
\hline
\end{tabular} \\
\hline
\end{tabular}

Percebe-se que o intuito do projeto não era somente levar os alunos para tocarem músicas em seus celulares ou tablets, mas também estimular a apropriação do aplicativo Perfect Piano, indo além e mostrando o que poderiam aprender por trás de cada melodia, e que ensinamentos aquela abordagem transmitia. Vale ressaltar a importância do projeto 
para o desenvolvimento integral dos alunos, já que também atuou na consolidação dos laços afetivos oportunizados, mesmo que remotamente.

$\mathrm{Na}$ semana que era enviada a videoaula, a professora abordava um conteúdo e solicitava as atividades a serem feitas pelos alunos. Os estudantes podiam realizar a atividade a partir de uma performance que variava entre cantar, dançar ou tocar canções mediante uso do aplicativo Perfect Piano. Além disso, eles também deveriam ensaiar durante a semana e realizar a devolutiva por meio de vídeos ou áudios, os quais eram editados e compartilhados nas redes sociais da escola. Já nas aulas efetivadas, por meio das ferramentas de videoconferências, os alunos executavam apresentações de canto, da dança e do dedilhar das canções nos seus próprios celulares ou tablets por intermédio do uso do aplicativo musical para toda a turma. O link da aula agendada era disponibilizado no grupo do projeto com o horário preestabelecido.

Além das apresentações dos alunos, a professora proporcionava dinâmicas, explorando fontes sonoras diversas, como as existentes no próprio corpo (palmas, voz, estalos e batidas), na natureza e em objetos cotidianos, reconhecendo os elementos constitutivos da música e as características de instrumentos variados.

Diante disso, é importante destacar que os momentos de descontração, brincadeiras, jogos e confraternizações virtuais durante os encontros do projeto assumem uma importância fundamental para a manutenção do vínculo entre os estudantes e a escola, pois todas aquelas ações se configuraram como formas de motivar os alunos diante do distanciamento social em meio ao contexto da pandemia. Para Santos (2020), o ensino remoto tem deixado suas marcas, em alguns casos, permitindo encontros afetuosos e boas dinâmicas curriculares.

\subsection{Metodologia Aplicada para Compartilhar o Desempenho dos Alunos a um Público Externo e para Avaliação dos Estudantes do Projeto}

Ao longo do ano, foram planejadas duas apresentações pelo Google Meet para apreciação de suas aprendizagens e experiências por um público externo, tendo como intuito valorizar a dedicação e o compromisso dos alunos que integravam o projeto. A primeira aconteceu na semana da criança, em que alunos do $1^{\circ}$ ao $5^{\circ}$ ano do Ensino Fundamental apreciaram as apresentações em conjunto com docentes e gestores. Os alunos do projeto ficaram à vontade para tocar ou cantar a canção que tivessem maior afinidade.

Já a segunda apresentação externa, ocorreu ao final do ano letivo de 2020, com o I Recital de Natal do Projeto Música e Tecnologia na Nossa Casa, contando com um público de alunos e professores do Núcleo de Tecnologia de Maracanaú-CE (NUTEM). A valorização do trabalho realizado durante o ano letivo pode ser evidenciada nas redes sociais por meio de depoimentos e postagens, tanto de alunos quanto de pais e profissionais da área, conforme exemplificada na Figura 2 a seguir.

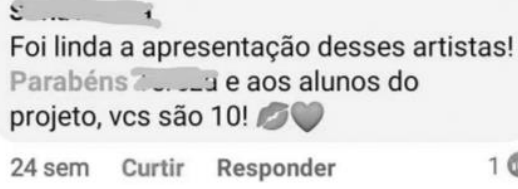

Figura 2: Depoimento de uma professora que prestigiou a apresentação

No questionário on-line realizado, quando questionados sobre a experiência de se apresentarem para um público externo, mesmo que de forma remota, alguns estudantes 
responderam: "Legal e divertido, mas dá nervoso" e "Toquei a canção bate o sino no Perfect Piano, foi uma ótima experiência, mas fiquei nervosa".

Ao final do ano letivo, os alunos foram avaliados pelo nível de comprometimento com as atividades do projeto. Os estudantes que participaram com mais de $60 \%$ de engajamento nas aulas do projeto receberam certificados no espaço físico da escola, respeitando os protocolos de segurança de saúde, totalizando 15 estudantes concludentes.

\section{Considerações Finais}

Neste artigo, foram expostos os resultados de uma pesquisa-ação de abordagem qualitativa realizada no modelo de ensino remoto, havendo o envolvimento entre pesquisadores e sujeitos. O objetivo que norteou o trabalho foi apresentar o projeto Música e Tecnologia na Nossa Casa, desenvolvido remotamente com 20 estudantes do $3^{\circ}$ ao $5^{\circ}$ ano do Ensino Fundamental de uma escola pública do município de MaracanaúCeará.

Diante das evidências, pode-se afirmar que os resultados da questão foram alcançados, desvelando como estratégias para a promoção do ensino de música na modalidade remota: a utilização de recursos digitais, como o Perfect Piano, o Google Meet, o Messenger, o WhatsApp e outras TDIC a partir da criação de um projeto musical, ocorrendo, então, a combinação de estudos teóricos e práticos pela multidisciplinaridade de conteúdos envolvidos com a música; o uso de brincadeiras; jogos; confraternizações virtuais e a exposição das habilidades desenvolvidas pelos alunos mediante eventos culturais para um público externo.

Todas as estratégias utilizadas no projeto possibilitaram a relação, o entrosamento e a expressão de afetividade entre os estudantes em meio à pandemia. Ao utilizar os grupos de WhatsApp e as plataformas digitais de videoconferências como formas de comunicação, foi possível perceber o quanto as crianças interagiam, tiravam dúvidas, relatavam preocupações com os pares que adoeciam e expressavam, a todo instante, os sentimentos de amor, amizade e saudades dos colegas, dos professores e da escola.

Observou-se que o uso do Perfect Piano pelos estudantes permitiu combinar os estudos teóricos e práticos, promovendo diferentes atividades educacionais e musicais de forma lúdica, prazerosa e objetiva.

Sobre os temas abordados no aprendizado das canções, o conhecimento multidisciplinar de conteúdos envolvidos com a música adquiridos pelos alunos foi fortemente vivenciado durante o projeto. Com isso, valorizou-se a cultura regional, além dos símbolos nacionais e locais, resgate às brincadeiras infantis, associação de cidadania com os princípios de respeito à diversidade, desenvolvimento de valores e de mensagens de esperança, favorecendo, então, a construção de vocabulários, repertórios diversificados e ressaltando os aspectos do desenvolvimento humano.

Portanto, evidenciou-se que mesmo em meio a todos os desafios típicos de um cenário desolador de pandemia, a realização do projeto possibilitou a manutenção do relacionamento, da motivação e do entusiamo dos estudantes para com a escola por intermédio da Educação Musical mediada por recursos digitais. Por fim, como trabalhos futuros, planeja-se realizar outras pesquisas voltadas ao ensino de música utilizando recursos digitais, verificando outras contribuições para o processo de ensino e aprendizagem das crianças. 


\section{Referências}

Barbosa, J.; Dourado, T. (2016). Tecnologias Móveis: Laptop XO e suas Contribuições para o Ensino de Música na Escola. Anais dos Workshops do Congresso Brasileiro de Informática na Educação, [S.1.], p. 866, nov. 2016. ISSN 2316-8889. Disponível em: $<$ http://www.br-ie.org/pub/index.php/wcbie/article/view/7010>. Acesso em: 02 set. 2021.

Barbosa, S. D.J e Silva, B. S da. (2010). Interação humano-computador. Rio de Janeiro: Elsevier, 2010. il. - (Série SBC, Sociedade Brasileira de Computação)

Brasil. (2016) "Leis de Diretrizes e Bases da Educação Nacional", 13.278 de 02 de maio de 2016. Brasília, MEC. Disponível em: http://www.planalto.gov.br/ccivil 03/ ato2015-2018/2016/lei/113278.htm Acesso em: 21 fev. 2021.

Brasil. Ministério da Educação. (2017) "Base Nacional Comum Curricular" (versão homologada pelo MEC em 20 de dezembro de 2017). Disponível em: http://basenacionalcomum.mec.gov.br/images/BNCC 20dez site.pdf Acesso em: 21 fev. 2021

Cantão, F. N. (2018) "Iniciação ao piano com suporte de novas tecnologias: uma análise preliminar do aplicativo maestro". XIV Encontro Regional Nordeste de Associação Brasileira de Educação Musical. Salvador. Disponível: http://www.abemeducacaomusical.com.br/conferencias/index.php/nd2018/regnd/pap er/view/2913/1604 Acesso em: 15 jan. 2021.

Chamorro, A.; Gitahy, R. C.; Terçariol, A. A. de L. e Santos, D. (2017) "Educação Musical e as Tecnologias Digitais: O Uso de Objetos de Aprendizagem e a Percepção dos Docentes". Revista Educação e Linguagens 6, $\mathrm{n}^{0}$ 11. Disponível em: http://www.fecilcam.br/revista/index.php/educacaoelinguagens/article/view/1651. Acesso em: 30 jun. 2021.

Cheng, L. e Leong, S.. (2017) "Educational Affordances and Learning Design in Music Software Development". Technology, Pedagogy and Education 26, n 4, p. 395-407. Disponível em: https://doi.org/10.1080/1475939X.2016.1267037 Acesso em: 06 jun. 2021.

Cifra Melódica (2021). [S.I]: Cifra Melódica. Disponível em: https://ciframelodica.com.br/ Acesso em: 30 jun. 21.

Correia, M. C. B. A observação participante enquanto técnica de investigação. Pensar Enfermagem Vol. 13 N. $^{\circ} 22^{\circ}$ Semestre de 2009. Disponível em: https://comum.rcaap.pt/bitstream/10400.26/23968/1/2009_13_2_30-36.pdf Acesso em: 12 ago. 2020.

Cota, D. M. (2016) “Aplicativos musicais: uma reflexão sobre a inovação da educação musical". Dissertação do Mestrado em Música pela Universidade Federal do Estado do Rio de Janeiro, Rio de Janeiro. Disponível em: http://www.repositoriobc.unirio.br:8080/xmlui/handle/unirio/11040 Acesso em: 12 ago. 2020.

Dourado, T. (2018) Concursos educacionais: experiências exitosas de projetos pedagógicos desenvolvidos no laboratório de informática da escola.. In: Workshop de Informática na escola, 24. , 2018, Fortaleza, CE. Anais [...]. Porto Alegre: Sociedade 
Brasileira de Computação, 2018 . p. 391-400. Disponível em: https://doi.org/10.5753/cbie.wie.2018.391 Acesso em: 16 set. 2021.

Duarte, A.M. (2014) “Aplicativos Musicais para tablets e smartphones: Novos Recursos para a Educação Musical." Trabalho de Conclusão de Curso ao departamento de Música da Universidade de Brasília. Brasília -DF.

Filippo, D.; Roque, G., Pedrosa, S. (2021). Pesquisa-ação: possibilidades para a Informática Educativa. In: Pimentel, M.; Santos, E. (Org.) Metodologia de pesquisa científica em Informática na Educação: abordagem qualitativa. Porto Alegre: SBC, 2021. (Série Metodologia de Pesquisa em Informática na Educação, v. 3 ) Disponível em: https://metodologia.ceie-br.org/livro-3/ Acesso em: 11 set. 2021.

Gohn, D. (2010) “Tecnologias digitais para educação musical.” São Carlos: EdUFSCar, p.66. Coleção UAB - UFScar.

Julia, J., Hakim, A. e Fadlilah, A. (2019a) "Shifting Primary School Teachers" Understanding of Songs Teaching Methods: An Action Research Study in Indonesia". International Journal of Education and Practice 7, no 3 (2019): 158-67. Disponível em: UJER26-19514689.pdf (hrpub.org) Acesso em: 21 fev. 2020.

Julia, J., Supriyadi, T., and Iswara, P.D. (2019b) "Using Android-based applications to support elementary school teachers to songs." Journal of Physics: Conf.Series 1318. IOP Publishing. Disponível em: https://iopscience.iop.org/article/10.1088/17426596/1318/1/012041 Acesso em: 21 fev. 2020.

Julia, J., Supriyadi, T., and Iswara, P.D. (2020) "Training the non-specialist music teacher: Insights from an Indonesian action research study". Universal Journal of Educational Research 8, no 2 (2020): 547-58.

Miyamoto, F. T. e Montanha, G. K. (2016) "Uso de Aplicativos para Dispositivo Móvel no processo de aprendizagem em escolas de música". In V JORNACITEC, 2016. Disponível em: http://www.jornacitec.fatecbt.edu.br/index.php/VJTC/VJTC/paper/view/702 Acesso em: 26 jun. 2021.

Mota, C. B. (2019) “O Uso de Softwares na Educação Musical.” Revista Educação em foco -Edição $\quad \mathrm{n}^{\circ} \quad 11 . \quad$ Disponível https://portal.unisepe.com.br/unifia/wpcontent/uploads/sites/10001/2019/05/002 OUSO-DE-SOFTWARES-NA-EDUCA $\% \mathrm{C} 3 \% 87 \% \mathrm{C} 3 \% 83 \mathrm{O}-M U S I C A L . p d f \quad$ Acesso em: 15 de janeiro de 2021.

Rodrigues, A. (2020) Ensino remoto na Educação Superior: desafios e conquistas em tempos de pandemia. SBC Horizontes, jun. 2020. ISSN 2175-9235. Disponível em: http://horizontes.sbc.org.br/index.php/2020/06/17/ensino-remoto-na-educacaosuperior/. Acesso em: 15 de janeiro de 2021.

Sant'Anna, D. de F. F. A. e Sant'Anna, D. V. (2020) "Google Meet como Modalidade de Ensino Remoto: Possibilidade de Prática Pedagógica". Anais do CIET:EnPED:2020 (Congresso Internacional de Educação e Tecnologias | Encontro de Pesquisadores em Educação a Distância), 28 de agosto de 2020. Disponível em: https://cietenped.ufscar.br/submissao/index.php/2020/article/view/1787 Acesso em: 15 de janeiro de 2021. 
Santos, E. (2020) "EAD, palavra proibida. Educação online, pouca gente sabe o que é. Ensino remoto, o que temos." Notícias, Revista Docência e Cibercultura. ISSN: 25949004. Disponível em: https://www.e-publicacoes.uerj.br/index.php/redoc/announcement/view/1119 Acesso em: 15 de janeiro de 2021.

Souza, G. L. de. (2019) “O Uso Pedagógico das Tecnologias Digitais de Informação e Comunicação (TDIC) na Formação do Cidadão Planetário." Dissertação de mestrado. Universidade Federal do Ceará, Faculdade de Educação, Programa de Pós- Graduação em Educação, Fortaleza- Ceará.

Souza, E. P. de. (2020) "Educação em tempos de pandemia: desafios e possibilidades." Cadernos De Ciências Sociais Aplicadas, 17(30), p. 110-118, 2020. Disponível em: https://doi.org/10.22481/ccsa.v17i30.7127 Acesso em: 15 de janeiro de 2021.

Volpe, M. (2019). Pedagogia da história da música brasileira, questões historiográficas em multidisciplinaridade. Revista Brasileira de Música, 32(1), 31-45. Disponível em: https://revistas.ufrj.br/index.php/rbm/article/view/29130. Acesso em: 09 set. 2021. 